\title{
Desmontagem do diagnóstico e orientação para o singular: apresentações de pacientes de Jacques Lacan
}

\author{
Cecília Lana Nascimento* (1) \\ Angela Vorcaro (1) \\ Universidade Federal de Minas Gerais, Faculdade de Filosofia e Ciências Humanas, \\ Departamento de Psicologia, Belo Horizonte, MG, Brasil
}

\begin{abstract}
Resumo: A empiria analisada neste artigo são as transcrições de três apresentações de pacientes conduzidas por Jacques Lacan no Hospital de Sainte-Anne, em 1976. A análise dessas entrevistas teve como objetivo apreender como Lacan procedia como analista no que diz respeito ao uso das categorias diagnósticas e ao manejo da tensão entre a universalidade do tipo clínico e a singularidade do caso único. A análise revelou que, embora Lacan não se recusasse a empregar termos oriundos da psiquiatria clássica nem a fazer o diagnóstico estrutural dos sujeitos entrevistados, esses aspectos não estavam no foco de seu interesse. Lacan prescindia da rigidez das categorias diagnósticas, realizando operações de desarme, inversão, anulação ou desmontagem do diagnóstico-padrão, inventando nomes - e não diagnósticos - que não fundavam novas classes para caracterizar os pacientes.
\end{abstract}

Palavras-chave: apresentação de pacientes, diagnóstico, classificação, universal, singular.

Este artigo tem como objetivo apreender algumas diretrizes acerca do modo como a psicanálise trata o impasse da classificação psicopatológica no tensionamento entre a universalidade do tipo clínico e a singularidade do caso único. Para verificar como Jacques Lacan lidava esse desafio epistêmico, propusemo-nos a interrogar sua prática clínica no que concerne ao manejo das categorias diagnósticas, por meio da análise de algumas de suas apresentações de pacientes realizadas em 1976.

Aposta-se, portanto, que as transcrições dessas apresentações de pacientes nos permitam trilhar as manobras e intervenções de Lacan durante a entrevista com o paciente, bem como flagrar a discussão posterior do caso com o público de psiquiatras e alunos para localizar o que se formalizava a partir da relevância dada a aspectos clínicos e relativos à categorização do sujeito entrevistado.

\section{Situando epistemologicamente o problema da classificação diagnóstica no campo da psicanálise}

Freud apontou a ambiguidade em torno da qual se coloca o problema do diagnóstico no campo da clínica psicanalítica. Ele levantou essa questão ainda em 1895, em um estudo intitulado "Psicoterapia da histeria" (1893-1895). Comentando a dificuldade de obter uma ideia pertinente de um caso de neurose sem tê-lo submetido a uma análise aprofundada, Freud (1923/2006) acrescenta que, antes de estar apto a apreender um caso em detalhe, era necessário estabelecer um diagnóstico para determinar a orientação

* Endereço para correspondência: cecilialana12@gmail.com do tratamento. Entretanto estabelecer precocemente um diagnóstico implicaria problematizar sua pertinência, só passível de confirmação após certo tempo de tratamento. Eis uma dificuldade prática, técnica.

Também do ângulo epistemológico, o diagnóstico é um problema, um ponto de tensão para o psicanalista: ao pressupor a inserção do sujeito em uma classe, a essência categorial do diagnóstico constrange a análise, interessada na singularidade.

Dessa forma, como bem colocou Marcus André Vieira (2001), o diagnóstico na clínica psicanalítica se configura, ao mesmo tempo, como um mal necessário e como um bem perigoso, isto é, como algo que deve ser buscado, mas jamais alcançado inteiramente - verdadeira solução de compromisso. É o que torna o diagnóstico um ponto sintomático para a psicanálise. Não é à toa que Lacan nos relembra o ensinamento de Freud segundo o qual devemos abordar cada "novo caso como se nada houvéssemos adquirido de suas primeiras decifrações" (Lacan, 1967/2003, p. 249).

No livro ¿Ni neurosis ni psicosis? (2015), a psicanalista Nieves Soria lembra que a prática psicanalítica repousa sobre uma grande versatilidade no que diz respeito ao "bom uso do diagnóstico" (p. 15). A autora observa que, em muitos casos, o analista consegue guiar suas intervenções levando em consideração a hipotética estrutura subjetiva do paciente, mas, em outros, ele precisa se guiar mais pela posição do sujeito do que pela consideração da estrutura. E há, ainda, casos em que o analista precisa se orientar por uma articulação ou combinatória entre a posição do sujeito e sua estrutura. A autora escancara, assim, que a prática do psicanalista 
se baseia em um cálculo e se orienta pela tensão entre o singular do caso e o universal das estruturas clínicas. Mostra, também, que não há regra de ouro na aplicação da prática diagnóstica para a condução de um tratamento.

Portanto há uma tensão na qual necessariamente o analista deve operar - tensão entre o tipo clínico e o caso único, entre o singular e o universal, entre o calculável e o incalculável. Lacan (1973/2003) faz algumas formulações sobre a estrutura e o tipo clínico:

Porque a questão começa a partir de que existem tipos de sintoma, existe uma clínica. Só que, vejam: ela é anterior ao discurso analítico e, se ele lhe traz uma luz, isso é seguro, mas não é certo. Ora, precisamos da certeza, pois só ela pode ser transmitida, ao se demonstrar. (p. 557)

Lacan (1973/2003) insiste afirmando que os tipos clínicos decorrem da estrutura, mas que

o que decorre da mesma estrutura não tem forçosamente o mesmo sentido. É por isso que só existe análise do particular: não é de um sentido único, em absoluto, que provém uma mesma estrutura, sobretudo não quando ela atinge o discurso. (p. 557, grifos nossos)

E, por fim, conclui que "os sujeitos de um tipo, portanto, não têm utilidade para outros do mesmo tipo. E é concebível que um obsessivo não possa dar o menor sentido ao discurso de outro obsessivo" (Lacan, 1973/2003, p. 557, grifos nossos). O fato de existir uma clínica significa que os sintomas podem ser "tipificáveis", o que possibilita alguma formalização do que encontramos em cada caso. Entretanto Lacan adverte que o discurso analítico não franqueia a clínica psiquiátrica que lhe é prévia.

$\mathrm{O}$ que pode ser descrito, fenomenológica ou semiologicamente, como sintoma histérico, obsessivo, fóbico ou psicótico muitas vezes não corresponde a uma estrutura que poderíamos nomear da mesma forma, pois a relação entre o tipo de sintoma e a estrutura não é direta. Mas Lacan vai além: mesmo os sintomas apresentados por sujeitos que poderiam ser classificados como pertencentes ao mesmo tipo clínico não respondem à mesma lógica, não cumprem para o sujeito a mesma função, o que coloca para o analista a necessidade de trabalhar sempre renunciando ao "quadro clínico" para privilegiar a clínica do caso.

\section{Apresentação de pacientes: Charcot, Clérambault e Lacan}

Historicamente, as apresentações de pacientes são um dispositivo utilizado pela medicina com propósitos de ensino. Trata-se, grosso modo, do exame público de um paciente por um especialista. $\mathrm{O}$ dispositivo se organizou classicamente em torno de uma entrevista feita por um médico a um paciente diante de uma plateia - geralmente composta por alunos e outros médicos e profissionais do serviço de saúde ou instituição de ensino em questão interessada em aprender a partir da observação. A função original das apresentações era, portanto, demonstrativa. Seu objetivo era ilustrar uma patologia.

Segundo Foucault (1973-1974/2006), o interrogatório psiquiátrico tinha finalidades claras: fazer o sujeito interrogado reconhecer a presença de um foco delirante naquilo que dizia e, mais que isso, fazer que mostrasse concretamente seu delírio durante o interrogatório: "Sim, escuto vozes! Sim, tenho alucinações! Sim, acredito que sou Napoleão! Sim, deliro!" (Foucault, 1973-1974/2006, p. 356).

O relato do enfermo se inscrevia em um saber dado de antemão. As respostas às perguntas do médico se encaixavam em categorias diagnósticas preestabelecidas que conformavam o saber psiquiátrico. $\mathrm{O}$ médico observava signos e chegava a um diagnóstico, por meio de perguntas definidas previamente, em uma sequência sempre reproduzida da mesma forma.

Uma das figuras mais célebres na história das apresentações de pacientes foi Jean-Martin Charcot (1825-1893), neurologista que inaugurou as investigações dos fenômenos histéricos. Apesar dos avanços conquistados por Charcot, ele foi uma figura controversa, em razão da maneira como objetificava as pacientes, fazendo experimentações teatrais. Foucault (1981) chegou a se referir a Charcot como "o personagem mais altamente simbólico do abuso do poder médico" (p. 122).

Quinet (2001) observa que as apresentações de pacientes conduzidas por Charcot não se diferenciavam muito do procedimento dos hipnotizadores de feiras circenses da época. Os pacientes eram expostos à verificação científica e ao interesse do público. Sua subjetividade e singularidade não estavam em jogo, e sua fala era levada em conta apenas para a confirmação de um saber prévio. O objetivo era demonstrar conhecimento para a plateia e contribuir para o avanço do saber científico.

Outro médico famoso pela realização de apresentações de pacientes foi Gaëtan Gatian de Clérambault (1872-1934), um dos maiores expoentes da psiquiatria francesa. O psiquiatra realizava suas observações clínicas na Enfermaria Especial da Prefeitura de Polícia de Paris, onde trabalhou por mais de trinta anos. Entre 1928 e 1929, foi professor de Lacan, que nessa época fazia seu internato em psiquiatria.

O fato de ter trabalhado na Enfermaria Especial de Polícia - um verdadeiro observatório da loucura possibilitou a Clérambault ter acesso a estados da psicose bastante incomuns. Além disso, como não tinha qualquer preocupação terapêutica - seu trabalho consistia apenas em decidir, a partir de uma avaliação psicopatológica, se um paciente seria encaminhado à cadeia ou ao hospital-, Clérambault teve bastante liberdade para investigar sem se ocupar em tratar, dando contribuições valiosas à psiquiatria.

As apresentações de pacientes conduzidas por Clérambault (1987) eram marcadas pela fineza na 
localização dos fenômenos e pela minúcia das observações clínicas, mas também por certa violência para com o paciente, uma vez que seu objetivo era extrair a confissão do delírio. As estratégias utilizadas pelo psiquiatra para conseguir essa confissão eram um tanto controversas.

Lacan aprendeu muito com a habilidade e a precisão diagnóstica de seu mestre, perpetuando, em suas apresentações de pacientes, a busca pela posição do doente, para além da mera localização dos fenômenos elementares. O interesse pelo elemento mínimo, formador da psicose, é certamente uma herança de Clérambault. No entanto, ao observar o mestre, Lacan também parece ter aprendido o que não deveria fazer: não "desocultar" o diagnóstico com violência, mas, ao contrário, escutar o sujeito no doente.

\section{A subversão lacaniana do dispositivo das apresentações de pacientes: extrai-se o singular para orientar o tratamento}

Lacan reinventou essa prática sob a ótica da psicanálise, servindo-se dela ao longo de todo o seu ensino. Mais que isso, as apresentações de pacientes parecem ter funcionado como uma espécie de fio condutor de seu ensino durante quase três décadas.

É curioso o fato de Lacan jamais ter aberto mão da realização das apresentações de pacientes, ainda que essa prática fosse duramente denunciada como um dispositivo de abuso de poder médico e de objetificação do paciente. Orientado pelo discurso da psicanálise, Lacan transformou a prática da apresentação de pacientes em um encontro com um analista e, assim, reconfigurou suas funções de ensino, diagnóstico, prognóstico e terapêutica a partir de uma clínica do sujeito do inconsciente. Como formalizou Quinet (2001):

Com Lacan, a apresentação adquiriu um novo significado, por ser de outro estilo: deixou de ser mostração e ilustração de quadros clínicos para se tornar entrevista, encontro, tiquê, em que o elemento surpresa, essencial na abertura do inconsciente, é fruto do acaso propiciado pelas circunstâncias. Nela, o analista não ensina, mas é ensinado, tal como quem assiste à apresentação, pelas formações do inconsciente do próprio paciente, que ocorrem durante a prática sempre como se fosse por acaso. (p. 87)

Além disso, para Lacan, a localização dos fenômenos elementares não tinha como objetivo a produção de um catálogo de exemplos ilustrativos para a aprendizagem dos alunos que compunham a plateia, mas a localização daquilo que sustentava o sujeito no laço social ou, contrariamente, daquilo que o fazia romper com o laço social. Conforme afirmou Lacan (1958/1998), cabe ao psicanalista, em uma apresentação de pacientes, a "submissão completa, ainda que advertida, às posições propriamente subjetivas do paciente" (p. 540).
No dispositivo lacaniano, o que estava em jogo para o público não era o aprendizado de noções ou de classificações das doenças mentais. Pelo contrário, se se aprendia alguma coisa, era que não se podia saber tudo sobre determinado sujeito. Afinal, conforme testemunharam Lazarus-Matet e Leguil (2010), Lacan jamais permitiria que sua apresentação se prestasse à constituição de um quadro ou que um único olhar sobre um caso se impusesse e se fixasse. "Nenhuma colocação do caso em série era aceitável a partir desse exercício rigoroso, mas continuamente aventurado. Uma entrevista se acabava, a história começava" (Lazarus-Matet \& Leguil, 2010, para. 21).

\section{As apresentações de pacientes de Jacques Lacan}

Serão analisados aqui os textos de três das apresentações de pacientes de Lacan, as quais foram realizadas em 6 de janeiro de 1976, 13 de fevereiro de 1976 e 9 de abril de 1976. Do ponto de vista metodológico, é importante dizer que, no total, tivemos acesso à transcrição de doze entrevistas: oito delas, traduzidas do francês para o espanhol, foram obtidas a partir do acesso a um documento de circulação interna da Federación de Foros del Campo Lacaniano-España ${ }^{1}$ As outras quatro, ainda datilografadas, integram parte do acervo pessoal do psicanalista Érik Porge (2009), que, aluno de Lacan, acompanhava, gravava e transcrevia as sessões de apresentações de enfermos em Sainte-Anne. Porge nos cedeu cópias de suas transcrições para a realização desta investigação.

A primeira decisão metodológica relativa à análise dos textos foi escolher analisar mais de uma apresentação de paciente, com o intuito de enxergar elementos e estratégias que se repetiam na condução da entrevista e na posterior discussão do caso. Em seguida, eliminamos do leque de possibilidades transcrições interrompidas antes do final da entrevista ou transcrições apenas do primeiro momento da apresentação, isto é, que não incluíam as discussões de Lacan com seus alunos. A seguir, decidimos incluir apenas as transcrições que contavam também com informações do prontuário do paciente, as quais eram geralmente apresentadas a Lacan poucos minutos antes da realização da entrevista. Por fim, selecionamos das apresentações que restaram aquelas em que a questão da discussão do diagnóstico estrutural ou da definição do tipo clínico era contemplada no segundo tempo da apresentação, ainda que indiretamente ou por meio de comentários enigmáticos.

\section{Apresentação de 6 de janeiro de 1976}

A Sra. S., também apelidada de Monique, 42 anos, foi entrevistada por Lacan quando se encontrava em vias

1 Documento disponibilizado on-line na página do psiquiatra e psicanalista francês Patrick Valas. Recuperado de https://bit.ly/31g4Joe 
de se divorciar do marido. Quando chegou a Sainte-Anne, expressava um sentimento de extrema incapacidade: pensava que não conseguiria ganhar dinheiro para garantir o sustento de sua filha de sete anos. Não se achava digna de viver. Acusava-se de ter feito mal às pessoas e de ser a vergonha da família. Queria ver sua filha e depois se matar. Sentia que o mundo lhe era hostil, achava que as pessoas a criticavam e cochichavam a seu respeito. Sentia-se espionada e escutada.

Os problemas da Sra. S. se iniciaram em janeiro de 1974, quando o marido - que há muitos meses mantinha uma relação extraconjugal descoberta por Monique na leitura de cartas - dormiu fora e não retornou para casa. Depois de esperá-lo em vão, Monique vivenciou o desencadeamento da psicose. Seguiu-se uma crise psicótica marcada por períodos longos de prostração e excitação catatônica, de descontrole esfincteriano e de comentários incoerentes. Meses depois, retomou o trabalho, sentindo-se "robotizada", "controlada", "influenciada" por uma força externa. Ao longo dessas crises, a Sra. S. cometeu duas tentativas de suicídio.

A Sra. S. situava a aparição dos primeiros fenômenos elementares no período da adolescência depois da entrevista com Lacan, fica claro, no entanto, que eles estavam presentes desde a infância, quando, aos quatro anos, ao ser castigada por uma cuidadora, sentiu que não era ela, e sim outra, quem recebia o castigo.

Um ponto a ser destacado nessa apresentação de paciente foi o fato de Lacan ter se esforçado para descortinar a presença dos fenômenos elementares, elucidar sua natureza e precisar a origem de suas ocorrências na vida da paciente. Ao comentar o caso, Czermak (1991a) enfatiza justamente a exuberância e a multiplicidade de fenômenos elementares presentes na vida de Monique desde a infância, sem que a psicose tivesse se desencadeado.

Aos 18 anos, Monique iniciou seus estudos de Medicina. Foi eliminada da faculdade depois de quatro exames fracassados e iniciou, então, seus estudos no curso de Fisioterapia, profissão que exerceu satisfatoriamente. $\mathrm{Na}$ conversa com Lacan, conseguiu expressar que fracassara nos exames da faculdade de Medicina porque, quando solicitada pelo professor a responder a uma questão, "parecia que havia uma que não conseguia agir, e outra que pensava, mas não conseguia se exprimir". Era assim que essa paciente descrevia o problema do duplo: "Pode-se dizer que há uma em pé, ao lado ou atrás, e outra sentada, e elas se desprezam. Tenho a impressão de que há uma pessoa ao lado ou atrás, que sou eu que não sei. . . Uma que sabe e outra que não sabe dizer" (Czermak, 1991a, p. 102).

Às vezes, falando em público, ela se perguntava se o interlocutor não percebia que não era ela quem falava. Fica claro que algo se desencadeava na paciente quando ela estava em posição de ser julgada ou avaliada, como na situação dos exames orais na faculdade de Medicina. Era como se a presença do duplo fosse correlata à ausência da paciente, cuja identidade vacilaria nos momentos em que era colocada à prova.

Em suma, como a exaustiva busca de Lacan constatou, os fenômenos elementares estavam lá desde os quatro anos de idade. E, no entanto, a psicose parecia estar muito bem compensada. Conforme consta na sessão destinada à construção clínica do caso, realizada após a apresentação da paciente, "a Sra. S. percebe seus breves fenômenos elementares como se eles não lhe colocassem muitas dúvidas, como se se inscrevessem em um registro familiar" (Lacan, 1975-1976, p. 30).

Uma vez que fica explícita a presença dos fenômenos desde tão cedo e de maneira tão familiar à paciente, o problema que se colocou - e foi essa a trilha que Lacan perseguiu na entrevista - foi saber o que tão eficazmente evitou o desencadeamento até a idade dos 40 anos. Em outras palavras: o que fez suplência à psicose por tanto tempo?

Para formular hipóteses sobre o que fazia suplência, estabilizando a psicose da paciente, Lacan procurou precisar as circunstâncias em que se produzira o desencadeamento da psicose da Sra. S. A paciente, então, revela o que precedera imediatamente seu primeiro surto: o fato de o marido não ter voltado para casa naquele dia e de, portanto, ter dormido fora pela primeira vez.

Quando a paciente se retira da sala de entrevista e tem início o segundo momento da apresentação, Lacan (1975-1976) comenta com seus alunos: "A psicose é mais comum do que pensamos. Está bastante estendida. É certo que há algo nela que não tem nada de psicótico e que não pôde suportar" (p. 50). Em seguida, afirma mais de uma vez que o que resta à equipe é apostar: "Aposto que ela vai retomar o que vocês acabaram de chamar de sua rotina; ela irá retomá-la" (Lacan, 1975-1976, p. 50).

Czermak, que não parece tão otimista quanto Lacan, relembra-o de que a paciente passara por períodos graves de desagregação no ano anterior: "Ela atravessou momentos catatônicos. Depois ela se internou em um período persecutório" (Lacan, 1975-1976, p. 50). Lacan concorda e até afirma abertamente tratar-se de um caso de psicose, mas prefere colocar o acento sobre a aposta de que o período de crise não se arrastaria: "É certo que em um ano ela teve um desencadeamento psicótico, falando claramente. A aposta nos leva aí. Quero dizer, que não vai durar" (Lacan, 1975-1976, p. 50).

E, por fim, antes de encerrar a discussão, Lacan (1975-1976) resume seus pontos de vista acerca daquele caso, lançando um comentário um tanto enigmático sobre a psicose de Monique: "Dá a impressão de que a psicose não venceu, de que não é onipresente (pp. 50-51). Perguntamo-nos: o que significaria que uma psicose não haveria de ter vencido? Que uma psicose não seria onipresente? Muito provavelmente, uma psicose que "não venceu" seria aquela que não se desencadeou ou que, mesmo uma vez desencadeada, teria boas chances de voltar em breve a se estabilizar, que não permaneceria desencadeada por tanto tempo. Vemos, assim, um Lacan 
que coloca a tônica da questão no estado encadeado ou desencadeado da psicose.

Sobre a loucura da Sra. S., a equipe clínica formula a seguinte conjectura: "se a Sra. S. não tivesse se deparado com seus fenômenos elementares, não seria ela simplesmente depressiva?" (Lacan, 1975-1976, p. 31). Na sessão intitulada "Elaboração", na qual encontramos uma construção teórica do caso realizada após a apresentação da paciente ${ }^{2}$, localizamos o seguinte questionamento, que talvez condense a provocação enigmática de Lacan: "Até que ponto a Sra. S. é psicótica?” (Lacan, 1975-1976, p. 30).

De fato, fica claro que, em diversos momentos da entrevista, o interesse de Lacan não está em localizar as anormalidades, as patologias - e ele o diz tanto direta quanto indiretamente para Monique: "Não estou absolutamente buscando o anormal" (Lacan, 1975-1976, p. 39).

\section{Apresentação de 13 de fevereiro de 1976}

O caso do paciente Gérard Primeau se tornou célebre no meio psicanalítico em razão de Lacan tê-lo mencionado na lição de 17 de fevereiro de 1976, no seminário O sinthoma. Lacan (1975-1976/2007) faz ali referência à apresentação desse paciente, dando destaque ao fenômeno das palavras impostas relatado por Primeau. Fica claro como o encontro com esse paciente permitiu que Lacan extraísse do caso um saber sobre o caráter parasitário da linguagem no ser falante, o que o ajudou a formular uma possível aproximação entre o Sr. Primeau e o escritor James Joyce, no que diz respeito à vivência do chamado fenômeno das palavras impostas.

À época da entrevista, Primeau tinha 26 anos e vinha apresentando uma piora progressiva dos sintomas persecutórios, a ponto de ter feito uma grave tentativa de suicídio, fato que precedera sua internação.

Os primeiros sintomas marcadamente psiquiátricos foram reconhecidos pela família quando Primeau tinha 15 anos, em decorrência de problemas comportamentais na escola. Aos 19 anos, foi hospitalizado pela primeira vez. O paciente acreditava ser a reencarnação de Nietzsche ou de Artaud. Desenvolveu a convicção de que precisava salvar a França do fascismo. Em certo ponto do desenvolvimento delirante, afirmou que descobrira pelo rádio que escutavam seus pensamentos. Primeau dizia-se um telepata emissor e, em decorrência disso, passou a insultar os vizinhos, que, segundo ele, escutavam-no por telepatia. Os chamados receptores conheciam todos os seus pensamentos. Segundo consta no prontuário do paciente, em 1975, Primeau já não conseguia mais nem conversar, pois alegava a presença de muitas palavras impostas. Os receptores conheciam absolutamente todos os seus pensamentos.

2 Cabe salientar que não é possível precisar quem é o autor dessa construção: se se trata de uma elaboração do psiquiatra Czermak, de uma construção de Lacan ou de um texto elaborado a várias mãos, com a contribuição de Lacan e dos demais médicos que assistiram à apresentação.
Durante a conversa com Lacan, é impressionante a clareza com que Primeau explica o fenômeno das falas impostas, revelando o que parece ser seu "sistema" delirante: sempre que uma sentença imposta - isto é, uma sentença da qual o paciente não era o autor e que não tinha conexão com o contexto do diálogo em questão emergia em seu pensamento, ele tentava automaticamente compensá-la ou rebatê-la com outra sentença, esta sob seu controle, a qual ele chamava de "sentença reflexiva", de modo que uma sentença sempre se sucedia à outra conectada por meio da conjunção adversativa "mas".

Lacan se deu conta de que as falas reflexivas eram um tratamento sinthomático que Primeau encontrara para não se deixar invadir completamente pelo automatismo mental. Para se defender ou para estabelecer uma "compensação" diante das sentenças impostas, Primeau deveria produzir uma "reflexão" ou um "pensamento reflexivo". As falas impostas seriam o que Lacan chamou de primeiro "degrau" da psicose de Primeau - nível que o paciente vinha conseguindo manter sob certo controle graças ao tratamento pelas falas reflexivas.

O mais preocupante, diria Lacan após a saída do paciente da sala de entrevista, seria o segundo "degrau" da psicose, uma espécie de avanço ou de desenvolvimento do automatismo mental, o qual Primeau chamou de telepatia. Lacan investiga a possibilidade de Primeau conseguir construir algum tipo de tratamento para regular a invasão causada pela telepatia, assim como fizera para "compensar" as falas impostas, mas o cenário não parece favorável. Primeau deixou claro que apenas seria capaz de continuar vivendo caso o fenômeno da telepatia cessasse. Por esse motivo, o prognóstico de Lacan para Primeau não é positivo: "Não vejo nenhum modo como ele possa solucionar isso. Há tentativas de suicídio que terminarão exitosamente" (Lacan, 1975-1976, p. 103).

Um ponto particularmente curioso nessa entrevista consiste no fato de que Primeau, que era dotado de considerável erudição intelectual, construía teorias delirantes bastante complexas acerca do funcionamento da linguagem, as quais apresentavam certa familiaridade com o jargão da psicanálise. $O$ paciente fazia referências frequentes, por exemplo, a termos psicanalíticos como "real", "simbólico", "imaginário", "significante", "sonho" e "realidade". Na verdade, Primeau conhecia o trabalho de Jacques Lacan e já havia se interessado pela leitura de alguns de seus seminários e escritos. O comentário de Lacan sobre o caso, após o paciente deixar a sala, é breve, preciso e, ao mesmo tempo, enigmático:

Quando descemos aos detalhes, vemos que os trabalhos clínicos descritos nos tratados clássicos não esgotam a questão. Há alguns meses, examinei alguém que foi rotulado como um psicótico freudiano. Hoje, definitivamente, vimos uma psicose lacaniana... Verdadeiramente caracterizada. Com essas "falas impostas", imaginário, o simbólico e o real. . . Esse é um quadro clássico, que não se 
encontrará descrito, mesmo por bons clínicos, como Chaslin. É para ser estudado. (Lacan, 1975-1976, p. 103, grifos nossos)

Se pensarmos em termos de nosologia psiquiátrica clássica, Primeau poderia facilmente ter sido diagnosticado como um esquizofrênico paranoide. No entanto, segundo Lacan, os ditos de Primeau não permitiram que ele fosse enquadrado em nenhuma patologia mental já descrita por clínicos - nem mesmo bons clínicos como Chaslin, ele acrescenta. De modo surpreendente, Lacan nomeia o que extraiu do testemunho de Primeau como uma "psicose lacaniana", introduzindo nessa categoria seu nome próprio e, assim, diferenciando-o de outros quadros descritos pela psiquiatria. Para Lacan, então, Primeau seria um psicótico lacaniano, diagnóstico inventado com base no fato de esse paciente apresentar fenômenos de linguagem e um delírio telepático bastante ilustrativos do que a teoria lacaniana havia construído a respeito do parasitismo da linguagem. Eis a especificidade desse paciente. Eis, então, o que deveria ser levado em conta para nomeá-lo.

Quase um ano depois, em uma apresentação de paciente ocorrida em 2 de março de $1977^{3}$, Lacan procedeu de forma semelhante ao diagnosticar um paciente que se dizia ser a reencarnação do guru Aurobindo ${ }^{4}$. Durante a entrevista, tal paciente relatara ter experimentado sensações corporais "estranhas", como a de sair de seu próprio corpo e a de ter vivido por anos se alimentando de luz e pílulas de vitaminas. Havia desenvolvido teorias delirantes sobre os efeitos maléficos da alimentação e do sexo para o corpo e sobre a sacralidade do estômago. Após a saída do paciente, Lacan (comunicado em 2 de março de 1977) comentou com seus alunos: "Acho que é um esquizofrênico. . . É uma forma de esquizofrenia Aurobindiana". A palavra que Lacan escolheu para adjetivar a esquizofrenia é aquela que encarna a crença mais fundamental do paciente: a de ser o guru Aurobindo. Se era essa sua especificidade, então era dessa forma que Lacan nomeava o paciente, imprimindo, assim, no diagnóstico, aquilo que era único, exclusivo daquele sujeito.

\section{Apresentação de 9 de abril de 1976}

A Srta. Brigitte, de 27 anos, chegou a Sainte-Anne pensando estar sendo teleguiada por forças desconhecidas. Czermak (1991b) destaca que, no início de sua hospitalização, era impossível obter da paciente um discurso coerente. Brigitte possuía um estilo associativo particular, fundado sobre uma deriva, "um errar fora de qualquer rede significante própria” (Czermak, 1991b, p. 134).

3 A transcrição dessa entrevista nos foi cedida pelo psicanalista Érik Porge, que esteve presente nessa apresentação de paciente.

4 Sri Aurobindo foi um guru indiano. Desenvolveu uma filosofia sobre o progresso humano e a evolução espiritual, tendo sido o criador da modalidade Yoga Integral.

5 Material de acervo pessoal.
O que impressionou os psiquiatras no caso de Brigitte, a ponto de terem convidado Lacan para entrevistá-la, foi o fato de essa paciente, contrariando a regra geral das psicoses extraordinárias, não ter absolutamente nenhuma convicção, nenhuma fixidez. Em seu universo, nada era certo, tudo era intercambiável, todos os seres poderiam ser parecidos entre si. A dúvida que acometia Brigitte, como afirmou Czermak (1991b), não mantinha uma flutuação, sendo muito distinta, portanto, da dúvida que acomete o obsessivo, o qual recua sempre diante do ato que o levaria à certeza. Tratava-se de uma maneira especial de duvidar, na qual nada do dizer do outro tinha valor de orientação.

Como os relatos da paciente eram vagos, Lacan não conseguiu precisar se a desorganização psíquica de Brigitte se agravara em decorrência de sua demissão do cargo de cuidadora que ocupava em um lar de crianças, do encontro amoroso com um homem que a engravidou e, posteriormente, abandonou-a, da ocorrência da gravidez ou do nascimento do filho. Lacan tenta esmiuçar esses eventos à procura de algo que possa orientar a direção do tratamento de Brigitte, mas a investigação não o leva muito longe.

Lacan tentou investigar também a presença de possíveis construções delirantes, traços paranoides, fenômenos de influência, automatismos mentais, mas nada disso se mostrou muito consistente, a não ser a permanência radical da dúvida. Brigitte oscilava entre dizer que a perseguição de que era alvo era uma "lorota" e afirmar que ela era realmente perseguida. Uma das construções delirantes contadas por ela a Lacan o fato de que uma mulher haveria roubado seu xale e de que andava com ele pelas ruas - não tinha consistência alguma. A tal mulher acusada de roubar seu xale e também, posteriormente, sua identidade - não encarna verdadeiramente a figura de uma perseguidora. Sobre isso, Lacan (1993) afirma, ao final da entrevista: "Se ela reconheceu seu xale sobre uma companheira, não manifestou nada à pessoa em questão, não pensou em lhe perguntar o porquê da coisa... Tudo o que ela diz é absolutamente sem peso" (p. 31).

Já nos primeiros minutos da entrevista, Brigitte revela a Lacan o que parece sustentar sua existência: ela quer que a valorizem, quer encontrar um lugar e, sobretudo, precisa que este seja um lugar valorizado. No entanto vai ficando claro que a questão da necessidade de se sentir valorizada e de encontrar para si um lugar é vivida com certa radicalidade e literalidade por essa paciente: encontrar um lugar para si é uma função que orienta sua vida, mas, ao mesmo tempo, trata-se de uma tarefa impossível, uma vez que ela não tem "nenhuma referência".

Ao mesmo tempo em que se queixa de ser uma "substituta" e de não ter seu valor reconhecido, Brigitte afirma que a condição de sua existência é continuar substituindo pessoas, tomando a vida de outros. Ela está sempre em busca de tomar de empréstimo a imagem do outro sem, contudo, conseguir essa apropriação. 
Em certo momento, Lacan (1993) consegue recolher uma informação fundamental com relação à posição subjetiva dessa paciente: segundo Brigitte, ela sempre fora, desde a infância, uma pessoa "que substituía outra", pois ocupava o lugar da mãe no cuidado com os irmãos menores sempre que esta se ausentava por ocasião de uma nova gravidez.

Ao fim da entrevista, Brigitte se vale de uma metáfora esclarecedora de sua posição subjetiva: "Eu gostaria de viver suspensa como um vestido, se eu fosse anônima, eu poderia escolher a roupa na qual estou pensando, eu vestiria as pessoas a meu modo, eu sou um pouco um teatro de marionetes" (Lacan, 1993, p. 22, grifos nossos). Lacan se vale da metáfora do vestido suspenso para formalizar o caso de Brigitte na conversa com a equipe do Hospital. Quando a paciente sai da sala, ele comenta:

Ela não tem a menor ideia do corpo que tem para colocar dentro desse vestido. Não há ninguém para habitar a vestimenta. Ela é este pano. Ilustra o que eu chamo de semblante. Ela é isto. Há uma vestimenta e ninguém para se colocar ali dentro. Ela não tem relações existentes, a ideia de relações entre um certo número de pessoas apenas com vestimentas, é tudo o que existe para ela. (Lacan, 1993, p. 30)

Ao fazer tal afirmação, Lacan evidentemente insere Brigitte no campo da psicose, pois, se ela "não tem a menor ideia do corpo que tem", é porque algo na articulação entre os três registros que garantiria a consistência corporal falhou. Brigitte tenta se apropriar da vestimenta de outras pessoas, sem jamais conseguir se fixar em uma delas.

Há um ponto especificamente curioso no comentário que Lacan faz da entrevista com Brigitte no que diz respeito ao diagnóstico. É uma das raras vezes em que Lacan utiliza termos da psiquiatria clássica para caracterizar um caso - e ele o faz de maneira subversiva. Lacan (1993) afirma: "Kraepelin isolou esses curiosos quadros. Pode-se chamar isso uma parafrenia, e, por que não, assinalá-la com o termo de imaginativa?" (p. 30, grifo nosso). Ao incluir Brigitte na tal categoria das parafrenias imaginativas, Lacan customiza uma nosologia única, um diagnóstico que guarda relações com a semiologia dos clássicos, ressuscitando um termo psiquiátrico já dado ao esquecimento, a parafrenia, e dando-lhe uma especificação inédita: "imaginativa". Segundo Czermak (1991b), a clínica francesa chamaria casos como esse de "delírios da imaginação", enquanto a clínica alemã adotaria o nome de "parafrenias confabulantes". Mas, a rigor, a característica "imaginativa" não se refere a nenhum dos quatro tipos de parafrenia estabelecidos por Kraepelin: as parafrenias sistemática, confabulante, expansiva e fantástica. Dessa forma, como nos diz JeanClaude Maleval (1998), surpreso com o diagnóstico lacaniano, a acepção dada por Lacan nessa apresentação resulta muito original... uma inovação nosológica.

Além de original, trata-se de um uso despretensioso das categorias da psiquiatria clássica, como se Lacan soubesse que não se deveria levar tão a sério as taxonomias e se autorizasse a "jogar" com essas nomenclaturas algo semelhante ao que ele faz quando brinca com o diagnóstico do Sr. Primeau, classificando-o como um caso de "psicose lacaniana".

E, no entanto, ainda que tenha falado claramente em uma parafrenia, antes de se servir disso para comprovar a psicose, Lacan afirma, ao contrário, que o caso o levou a pensar justamente na dificuldade de se delimitar os limites da doença mental. Sobre o quadro de Brigitte, diz ainda que "não é uma séria doença mental observável, caracterizada ... ela vai fazer parte do número desses loucos normais que constituem nosso ambiente" (Lacan, 1993, pp. 30-31). Dessa forma, Lacan indica como psicose e loucura não caminham juntas.

Subdivisões nosológicas e classificações à parte, Lacan finaliza o comentário da entrevista retomando a orientação que a própria paciente lhe dera nos primeiros minutos de conversa e, assim, insinuando que a chave da direção do tratamento poderia passar por uma obviedade, por uma banalidade: "Ela quer se valorizar, que a valorizem, se puderem" (Lacan, 1993, pp. 30-31).

\section{Algumas hipóteses e constatações}

Ao nos perguntarmos sobre como Lacan lidava com a tensão entre a singularidade do caso clínico e a universalidade das perspectivas classificatórias, o que se mostrou foi o quanto Lacan operava livremente com as categorias diagnósticas da psiquiatria, no sentido de prescindir de sua rigidez, para se orientar por detalhes da história dos sujeitos entrevistados - detalhes esses reveladores do modo singular como esses sujeitos respondiam ao real da estrutura e conseguiam se colocar no laço social. Perguntar pelo diagnóstico, então, nos levou a perceber que era sobre outros aspectos que Lacan colocava ênfase, como o momento do surgimento dos fenômenos elementares e os fatores que levavam ao desencadeamento ou à estabilização do sujeito em cada caso, por exemplo.

No caso da Sra. S., embora Lacan (1975-1976) afirme que "a psicose é mais comum do que pensamos" (p. 50) e que, dessa forma, indique que se trata de fato de um caso de psicose, ele parece logo em seguida "flexibilizar" ou "suavizar" essa constatação, ao acrescentar que há algo na paciente "que não tem nada de psicótico" (Lacan, 1975-1976, p. 50). Em outras palavras, Lacan prefere colocar o acento sobre a aposta de que o período de desestabilização não se arrastaria. Além disso, ao afirmar que, no caso de Monique, a impressão que se tinha era "de que a psicose não venceu" (Lacan, 1975-1976, p. 51), ele indica implicitamente que é menos importante 
o diagnóstico de psicose em si e mais importante a possibilidade de apostar em uma futura estabilização.

É importante marcar, para além disso, a título de exemplo, que, embora alguns dados do caso nos permitam cogitar a hipótese de uma esquizofrenia e outros apontem para uma tonalidade melancólica, em momento algum Lacan tenta incluir a paciente em uma dessas classes. Ele prefere explorar outras vias na discussão do caso com a equipe.

No caso de G. Primeau, Lacan inventou a categoria diagnóstica "psicose lacaniana", customizando um diagnóstico a partir do traço mais singular daquele paciente e, assim, recusando-se a classificá-lo de acordo com categorias da psiquiatria clássica, as quais, segundo ele, seriam insuficientes para descrever aquele caso. A denominação "psicose lacaniana", nesse sentido, seria mais um nome isento de intenção classificatória do que propriamente um diagnóstico.

$\mathrm{Na}$ discussão do caso da Srta. Brigitte, testemunhamos uma das poucas vezes em que Lacan se vale de um termo da psiquiatria clássica para designar um tipo clínico, a parafrenia, e, no entanto, constata-se que seu emprego é feito de maneira original, despretensiosa ou mesmo subversiva, ao lhe ser acrescentado o subtipo "imaginativa", inventado pelo próprio Lacan. Assim, apesar de arriscar a determinação de um tipo clínico, semelhante ao que fez com Primeau, tal epíteto funciona mais como nome do que como classificação. Mais importante que o diagnóstico é o detalhe que orienta o caminho para uma possível estabilização: Brigitte precisa se sentir valorizada.

$\mathrm{Na}$ transcrição de uma das apresentações de pacientes que nos foi cedida por Érik Porge, como também já mencionamos, Lacan (comunicado em 2 de março de 1977) nomeia - e não classifica - o paciente, o qual acreditava ser a reencarnação do guru Sri Aurobindo, como sendo um "esquizofrênico aurobindiano" .

Soria (2015) parece ter capturado o espírito do uso lacaniano das categorias diagnósticas, reafirmando a expectativa lacaniana de que os psicanalistas pudessem inventar categorias diagnósticas próprias, indicando o limite da herança psiquiátrica que, como vimos, traz luz, mas não certeza (Lacan, 1973/2003).

Da parte de Lacan, o esforço para esboçar novas classificações se fez contingencialmente, em diferentes e pontuais situações, de uma maneira que Soria (2015) caracteriza como "irônica" (p. 16). A autora nos faz recordar o comentário de Lacan (1958) quando este propõe o diagnóstico de "anorexia mental" para um sujeito que não se hesitaria em classificar como sendo um neurótico obsessivo:

Alguém que não padecia de nenhum tipo de transtorno alimentar e encontrava-se obcecado pela ideia de que plagiava. Lacan faz um diagnóstico

6 Material de acervo pessoal irônico ao articular uma relação entre a anoréxica que come o nada e esse paciente que acreditava que roubava as ideias dos outros quando, na verdade, não roubava nada, e que, com relação à alimentação, não apresentou mais do que um sutil acting out no decorrer das sessões em que o analista em questão o confrontava com a realidade. (Soria, 2015, p. 17).

Ao mencionar a apresentação da paciente Brigitte, Soria destaca o diagnóstico lacaniano de "parafrenia imaginativa", inserindo-o na mesma lógica de funcionamento do diagnóstico inventado por Lacan para o Homem dos Miolos Frescos: ao propor classificações como as de "anorexia mental" e "parafrenia imaginativa", Lacan faz operações de desarme ou de desmontagem do diagnóstico padrão, o qual é regido pela fenomenologia dos sintomas (Sória, 2015). Ao mesmo tempo, se, por um lado, Lacan desmonta ou desarma as categorias da psiquiatria clássica, por outro, como observa Soria (2015), não propõe oficialmente nenhuma nova semiologia. Suas invenções não fundam novas classes.

Isso nos leva a concluir que, ao propor nomes como "parafrenia imaginativa", "psicose lacaniana", "anorexia mental" e "esquizofrenia aurobindiana", a intenção de Lacan não é classificatória. Seu objetivo parece ser muito mais o de nomear a singularidade essencial do caso, o detalhe por meio do qual o tratamento pode se orientar. No lugar de um diagnóstico, então, Lacan atribui aos pacientes um nome, a exemplo dos nomes inventados por Freud para caracterizar seus casos clínicos mais célebres: os casos do "Homem dos lobos", do "Homem dos ratos", da "Jovem homossexual". Evidentemente, não se trata de diagnósticos, mas de nomeações escolhidas com base em detalhes que tocam algum ponto da economia de gozo dos pacientes cujo caso é relatado nas monografias clínicas.

\section{O impasse das classificações e as classes paradoxais}

Este estudo nos surpreende pela constatação de que Lacan não faz uso recorrente dos termos diagnósticos da psiquiatria clássica - ao menos não nas discussões do caso com a equipe clínica após as apresentações de pacientes. Descobrimos também que ele se abstém completamente da intenção classificatória ao fazer referências às tipologias clínicas. Assim, o que aprendemos com Lacan a partir da observação de seu fazer nas apresentações de pacientes é que a psicanálise pode fazer uso do tipo diagnóstico sem se comprometer com práticas classificatórias.

Segundo Teixeira (2009), se quisermos entender de que maneira os termos diagnósticos permitem tornar pensáveis, a partir de uma estrutura comum, as mais singulares situações clínicas, temos, portanto, que esclarecer a maneira pela qual a psicanálise autoriza uma tipologia do caso clínico e qual seria a relação dessa tipologia com o problema diagnóstico. As perguntas 
levantadas pelo autor são centrais para a discussão empreendida aqui.

Uma saída interessante para o impasse epistêmico das classificações na psicanálise seria a visada de Jean-Claude Milner (2006), ao propor a existência de agrupamentos ou de classes que não criam entre seus elementos nenhuma solidariedade, nenhuma comunidade. Tais elementos formariam um conjunto inconsistente, impossível de ser atualizado na simultaneidade de suas partes. Assim, o proferimento, por exemplo, de significantes como neurótico ou psicótico não convocaria nenhum agrupamento, mas apenas indicaria a possibilidade de se construir uma classe paradoxal.

$\mathrm{O}$ que seriam as classes paradoxais de que nos fala Milner? Seriam classes que, paradoxalmente, não convocam nenhum agrupamento, mas que designam apenas o fato de que cada elemento do grupo possui um ponto ou uma característica que é "inagrupável".

Milner (2006) esclarece que há uma diferença entre as classes da psicanálise - que podem ser compreendidas como paradoxais - e as da psiquiatria, ainda que a psicanálise se utilize, por herança, das mesmas nomenclaturas da psiquiatria. A diferença reside no fato de que, para a psiquiatria, as classes designam apenas similitudes com relação a elementos do mesmo grupo e oposições com relação a elementos de outros grupos, enquanto, para a psicanálise, os nomes são retomados na condição de semblante. O psicanalista deve saber que há algo em cada elemento de um grupo que, justamente, escapa aos padrões desse grupo.

Assim, para o psicanalista, "o nome de neurótico, de perverso ou de obsessivo nomeia ou finge nomear a maneira neurótica, perversa, obsessiva que tem um sujeito de ser radicalmente dessemelhante de qualquer outro" (Milner, 2006, p. 91). É importante ler com cuidado essa citação de Milner. Não queremos dizer a partir dela que é no interior dessas nomeações - "obsessivo", "neurótico", "histérico", "perverso", "psicótico" etc. - que reside a radical dessemelhança de cada sujeito. Sabemos que todo o ensino de Lacan se constrói no sentido de indicar que não é em função do pertencimento a essas classes que o sujeito se singulariza em sua radicalidade; pelo contrário: a radicalidade da dessemelhança surge justamente quando o sujeito abre mão daquilo que determina seu pertencimento a essas categorias e se identifica ao seu sinthoma. Acreditamos que, com a citação anterior, Milner (2006) pretende apenas indicar que, a despeito de um funcionamento que pode ser considerado mais ou menos típico, mais ou menos enquadrado em uma categoria clínica, cada sujeito tem sua maneira de ser radicalmente distinto de qualquer outro.

Poderíamos pensar, então, seguindo essa linha de raciocínio, que é possível, como mostrou Lacan, servirmonos dessas denominações sem intenção classificatória, mas as utilizando como se fossem conceitos típicos ideais, que simplesmente nos ajudariam a tornar pensável a pluralidade dos elementos presentes no sofrimento psíquico, sem deixar de levar em conta, a todo tempo, que há algo em cada sujeito de uma classe que resiste à integração completa e harmônica a essa mesma classe. É também o que nos ensina Miller (2006), ao afirmar que:

O universal da classe, seja ela qual for, nunca está completamente presente em um indivíduo. Como indivíduo real, pode ser exemplar de uma classe, mas é sempre um exemplar com uma lacuna. Há um déficit da instância da classe num indivíduo e é justamente por causa desse traço que o indivíduo pode ser sujeito, por nunca poder ser exemplar perfeito. (p. 23, grifos nossos)

Assim, segundo Miller (2006), o diagnóstico deve ser pensado como a arte de julgar um caso sem regra, decidindo, a cada caso, se uma regra se aplica. Em última instância, é o sujeito quem inventa a maneira segundo a qual ele submeterá seu caso à regra supostamente universal.

É importante ressaltarmos, contudo, que o fato de toda prática classificatória destituir o caso de sua unicidade em prol de sua inclusão em um grupo não significa que não haja formas generalizáveis e transmissíveis nos tipos clínicos e nem que não precisemos do diagnóstico. "Não podemos dizer que não há classificações possíveis, ou que as classificações são inúteis. Isso seria pensar que entre nós não necessitaríamos de uma língua comum. Precisamos de um uso comum do que nos permite qualificar o que ocorreu" (Laurent, 2008, p. 125). Além disso, o que é único, na experiência analítica, não se opõe ao que é típico. Pelo contrário, em um tratamento analítico, cabe ao psicanalista destacar, na unicidade do caso, aquilo que se repete.

Teixeira (2016) nos alerta para o fato de que recusar radicalmente o uso de termos diagnósticos é uma postura romântica, uma espécie de "fetichismo do singular" que nos impede de ir mais adiante. "A psicanálise não pode ficar indiferente ao problema da formalização que se requer de cada caso singular, e necessita, por conseguinte, encontrar um modo de articulação da singularidade subjetiva ao universal do discurso em que sua solução se transmite" (Teixeira, 2016, p. 347, grifo nosso).

A palavra articulação, destacada da citação, nos remete mais uma vez à palavra tensão, que empregamos com certa frequência aqui. Não se trata, então, de opor unicidade e tipicidade, singularidade e universalidade, mas de manter em funcionamento uma tensão, uma articulação, uma reflexividade entre essas perspectivas.

Lacan parece atuar como psicanalista justamente nesse ponto paradoxal, não se recusando a empregar termos diagnósticos, mas destituindo-os de qualquer valor de conhecimento a priori. Talvez seja por essa razão que Miller (1996) tenha observado que, após a saída de um paciente da sala de apresentações de Lacan, a espera do pronunciamento de um diagnóstico por parte da audiência era sempre decepcionante, pois a maneira como Lacan desmontava, invertia ou anulava o emprego 
convencional das tipologias clínicas acabava levando sempre a mais um ciframento.

Evidentemente, as operações de desmontagem do diagnóstico-padrão podem ser compreendidas como atos ou intervenções clínicas que tinham como finalidade produzir na própria equipe clínica efeitos de suspensão de sentido para pensar o caso além do quadro psiquiátrico. Afinal, as apresentações de pacientes se passavam em um contexto absolutamente psiquiátrico - realizadas dentro de um hospital e voltadas para um público, em sua maioria, composto por médicos psiquiatras.

Se, com relação ao diagnóstico, Lacan provocava a suspensão do sentido, fazendo que restasse sempre ali algo enigmático, por outro lado, com relação ao esclarecimento e à investigação dos aspectos que sustentavam (ou não) o paciente no laço social, promovendo uma estabilização ou um desencadeamento, Lacan era límpido?

Em suma, a perspectiva de Lacan poderia ser definida, como uma vez afirmou Miller (2011), como antidiagnóstica. Este seria exatamente o ponto de vista de Lacan: desarmar ou desmontar a preocupação diagnóstica e fazer valer uma orientação para o singular, cujo interesse principal seria extrair do caso o traço, sua marca de pura diferença. Isso significa que se pode até levar o diagnóstico em conta, desde que o objetivo seja se orientar para avançar para além dele. Os nomes que Lacan introduziu nos diagnósticos dos doentes apresentados apontam justamente para a identidade singular de cada um deles, libertando-os, portanto, da semelhança com os diagnósticos clássicos. Perguntamo-nos, então, se o que interessaria ao analista não seria, no lugar de definir um diagnóstico psiquiátrico ou mesmo estrutural, realizar a construção do caso seguindo a rigorosa lógica lacaniana de rastreamento de sintomas e soluções sinthomáticas para, então, extrair do caso a marca de gozo. Em outras palavras, propomos que o diagnóstico propriamente psicanalítico equivaleria ao exercício de construção do caso e à subsequente decantação ou escrita do traço que o singulariza.

\section{Disassembly of diagnosis and orientation towards the singular: Jacques Lacan's patient presentations}

Abstract: This article analyzed the transcriptions of three patient presentations conducted by Jacques Lacan at the Hospital of Sainte-Anne in 1976. The analysis of these interviews aimed to apprehend how Lacan proceeded as an analyst with respect to the use of diagnostic categories and the management of the tension between the universality of the clinical type and the singularity of the single case. The analysis revealed that although Lacan did not refuse to use terms derived from classical psychiatry or to make the structural diagnosis of the interviewed patients, these aspects were not the focus of his interest. Lacan dispensed the rigidity of diagnostic categories, performing disarmament, inversion, annulment or disassembling operations of the standard diagnosis, inventing names - and not diagnoses - that did not establish new classes to characterize patients.

Keywords: presentation of patients, diagnosis, classification, universal, singular.

\section{Démontage du diagnostic et orientation au singulier: présentations des patients de Jacques Lacan}

Résumé: Cet article analyse l'étude empirique composée par les transcriptions de trois entrevues de patients menées par Jacques Lacan à I'Hôpital de Sainte-Anne, en 1976. Cette analyse visait à comprendre comment Lacan procédait en tant qu'analyste à l'égard de l'utilisation des catégories diagnostiques et de la gestion des tensions entre l'universalité du type clinique et la singularité du cas unique. L'analyse a révélé que, bien que Lacan ne refusât pas d'utiliser des termes issu de la psychiatrie classique ou de faire le diagnostic structurel des sujets interrogés, ces aspects n'étaient pas au centre de son intérêt. Lacan s'est dispensé de la rigidité des catégories diagnostiques, effectuant le démontage, l'inversion, l'annulation ou le désassemblage du diagnostic standard, en inventant des noms - et non des diagnostics - qui n'ont pas trouvé de nouvelles classes pour caractériser les patients.

Mots-clés: présentation des patients, diagnostic, classification, universel, singulier.

\section{Desmontaje del diagnóstico y orientación para el singular: presentaciones de pacientes de Jacques Lacan}

Resumen: En este artículo se analizan las transcripciones de tres presentaciones de pacientes conducidas por Jacques Lacan en el Hospital de Sainte-Anne, en 1976. El análisis de esas entrevistas tuvo como objetivo aprehender cómo Lacan procedía

7 Isso se verificou não apenas nas três apresentações de pacientes analisadas aqui, mas também nas outras nove a que tivemos acesso e que acabaram não sendo especificamente trabalhadas neste artigo. 
como analista en lo que se refiere al uso de las categorías diagnósticas y al manejo de la tensión entre la universalidad del tipo clínico y la singularidad del caso único. El análisis reveló que, aunque Lacan no se negaba a emplear términos oriundos de la psiquiatría clásica ni a hacer el diagnóstico estructural de los sujetos entrevistados, esos aspectos no estaban en el foco de su interés. Lacan prescindía de la rigidez de las categorías diagnósticas, realizando operaciones de desarme, inversión, anulación o desmontaje del diagnóstico estándar, inventando nombres -y no diagnósticos- que no fundaban nuevas clases para caracterizar a los pacientes.

Palabras clave: presentación de pacientes, diagnóstico, clasificación, universal, singular.

\section{Referências}

Clérambault, G. G. (1987). Oeuvres psychiatriques. Paris: Frénésie Éditions. (Trabalho original publicado em 1942)

Czermak, M. (1991a). Sobre alguns fenômenos elementares da psicose. In M. Czermak, Paixões do objeto: estudo psicanalítico das psicoses (pp. 99-118). Porto Alegre, RS: Artes Médicas.

Czermak, M. (1991b). Sobre um problema de nosografia das psicoses. In M. Czermak, Paixões do objeto: estudo psicanalítico das psicoses (pp. 131-138). Porto Alegre, RS: Artes Médicas.

Foucault, M. (1981). A casa dos loucos. In M. Foucault, Microfísica do poder (pp. 113-128). Rio de Janeiro, RJ: Edições Graal.

Foucault, M. (2006). O poder psiquiátrico: curso dado no Collège de France (1973-1974). São Paulo, SP: Martins Fontes.

Freud, S. (2006). Neurose e psicose. In Edição standard brasileira das obras psicológicas completas de Sigmund Freud (J. Salomão, trad., Vol. 19, pp. 165-171). Rio de Janeiro, RJ: Imago. (Trabalho original publicado em 1923)

Lacan, J. (1975-1976). 8 presentaciones de enfermos en Sainte-Anne. San Sebastian: Federación de Foros del Campo Lacaniano. Recuperado de https://bit.ly/318AEi8

Lacan, J. (1998). De uma questão preliminar a todo tratamento possível da psicose. In Escritos (V. Ribeiro, trad., pp. 537-591). Rio de Janeiro, RJ: Zahar. (Trabalho original proferido em 1957-1958)

Lacan, J. (1993). Documento: O caso de Mademoiselle B. Relato de uma apresentação de paciente feita por J. Lacan. Psicose: Revista da Associação Psicanalítica de Porto Alegre, 4(9), 3-31.

Lacan, J. (2003). Proposição de 9 de outubro de 1967 sobre o psicanalista da Escola. In Outros escritos (V. Ribeiro, trad., pp. 248-264). Rio de Janeiro, RJ: Zahar. (Trabalho original publicado em 1967)

Lacan, J. (2003). Introdução à edição alemã de um primeiro volume dos Escritos. In Outros escritos (V. Ribeiro, trad., pp. 550-556). Rio de Janeiro, RJ: Zahar. (Trabalho original publicado em 1973)

Lacan, J.(2007). Oseminário, livro 23: osinthoma, 1975-1976. Rio de Janeiro, RJ: Zahar.
Laurent, E. (2008). A classificação. Opção Lacaniana: Revista Brasileira Internacional, (51), 120-130.

Lazarus-Matet, C., \& Leguil, F. (2010). Lacan en Sainte-Anne. Consecuencias: Revista Digital de Psicoanálisis, Arte y Pensamiento, (5). Recuperado de https://bit.ly/3j0DuE6

Maleval, J.-C. (1998). El consentimiento regulado del goce del Outro. In J.-C. Maleval, Lógica del delírio (pp. 219-252). Barcelona: Ediciones del Serbal.

Miller, J-A. (1996). Lições sobre apresentações de doentes. In J.-A. Miller, Matemas I (pp. 138-149). Rio de Janeiro, RJ: Zahar.

Miller, J.-A. (2011). Sutilezas analiticas (2008-2009). Buenos Aires: Paidós.

Milner, J.-C. (2006). Os nomes indistintos. Rio de Janeiro, RJ: Companhia de Freud.

Porge, E. (2009). Apresentação de paciente: uma clínica da apresentação. In E. Porge, Transmitir a clínica psicanalitica: Freud, Lacan, hoje (pp. 223-235). Campinas, SP: Editora Unicamp.

Quinet, A. (2001). A apresentação de pacientes de Charcot a Lacan. In A. Quinet (Org.), Psicanálise e psiquiatria: controvérsias e convergências (pp. 83-90). Rio de Janeiro, RJ: Rios Ambiciosos.

Soria, N. (2015). La función del diagnóstico en psicoanálisis. In N. Soria, ¿Ni neurosis ni psicosis? (pp. 13-30). Buenos Aires: Ediciones Del Bucle.

Teixeira, A. M. R. (2009). Do tipo clínico como semblant. In T. C. Santos (Org.), Inovações no ensino e na pesquisa em psicanálise aplicada (Vol. 1, pp. 13-21). Rio de Janeiro, RJ: Sete Letras.

Teixeira, A. M. R. (2016). Neurose, psicose, perversão: a implicação do sujeito na nosologia freudiana. In S. Freud, Obras incompletas de Sigmund Freud: neurose, psicose, perversão, (J. Strachey, trad., pp. 327-348). Belo Horizonte, MG: Autêntica.

Vieira, M. A. (2001). Dando nome aos bois, sobre o diagnóstico em psicanálise. In A. C. Figueiredo (Org.), Psicanálise, pesquisa e clínica (Vol. 1, pp. 171-181). Rio de Janeiro, RJ: Ipub.

Recebido: $23 / 04 / 2018$

Revisado: 02/09/2019 Aprovado: 05/08/2020 